\title{
Intercollegiate Board for Sport and Exercise Medicine
}

Establishing a new medical discipline in the United Kingdom must meet a series of criteria laid down by the European Medical Specialist Qualification Order, the General Medical Council, and the Specialist Training Authority (STA). Enthusiastic practitioners of sport and exercise medicine must meet the demands of these bodies before the National Health Service medical education unit will recommend that the secretary of state for health should amend schedule 2 of the Specialist Medical Order.

There is a reluctance in the STA to increase the number of specialties. Any proposal to support the recognition of sport and exercise medicine will need to be soundly based and closely argued, demonstrating that an identified need for the specialty can be met by appropriately trained doctors.

Postgraduate medical training in the United Kingdom is based on doctors spending one year as a preregistration house officer followed by a minimum of two years general professional/basic specialty training giving a breadth of experience before the doctor chooses a higher specialty training programme. These supervised programmes vary from a minimum of one year in general practice to four to six years in hospital based or community medicine specialties. Thereafter, the doctor applies to the STA for recognition that his/her training has been completed. This entitles the doctor to have his/her name added to the specialist medical register with an agreed suffix acknowledging the specialty.

This is the background against which the Intercollegiate Academic Board for Sport and Exercise Medicine was established with the support of the Academy of Medical Royal Colleges in April 1998. The board's first priority has been to develop a diploma examination, building on the experience of the Scottish Royal Colleges, which will set the minimum standards of knowledge and "touch line skills" for doctors practising sport and exercise medicine. This examination is pitched at a similar standard to the membership examinations in medicine and surgery, and acknowledges the completion of basic specialty training. In due course, the examination will be an entry requirement for higher specialty training in sport and exercise medicine.

The first part of the examination consists of a multiple choice question paper (two hours duration), of which about one third of the questions cover the basic sciences, and three short essay questions (one hour). Candidates must pass part I before they enter part II, which consists of a 30 minute oral followed by two 30 minute objective structured clinical examinations designed to assess core and clinical skills.

The board has issued a syllabus and reading list to help the candidates, who come from a wide range of backgrounds, to prepare for the examination. Details of suitable educational courses run by the British Association of Sport and Exercise Medicine and several universities can be obtained from the National Sports Medicine Institute.

The board has clarified the steps that need to be put in place to establish higher specialty training programmes in sport and exercise medicine. Individual specialty advisory committees supervise and accredit training programmes, trainers, and trainees before recommending a successful trainee to the STA. A common feature of all specialties is that trainees can apply for a flexible year to undertake additional relevant training or research. Rehabilitation medicine currently allows trainees to spend a year in sport and exercise medicine. The Intercollegiate Board of Sport and Exercise
Medicine hopes to persuade more specialty advisory commit tees, ranging from orthopaedics and trauma to rheumatology, occupational medicine, or public health to view sport and exercise medicine as a suitable flexible training year.

Developing a four year full time higher specialty training programme in sport and exercise medicine that will meet the requirements of the STA, as outlined above, will require an enormous commitment, looking at European, North American, and Australasian experience as well as coordinating clinical and educational opportunities. The number of centres able to offer a full programme will be limited. The Intercollegiate Academic Board of Sport and Exercise Medicine would welcome approaches from centres who would be prepared to develop suitable programmes for what will initially be a small number of trainees to meet the requirements of Great Britain and Ireland. The momentum to develop one year and four year higher specialty training programmes has recently been accelerated by correspondence between Ms Kate Hoey, MP, Minister for Sport and the Chairman of the Academy of Medical Royal Colleges which accepts that sport and exercise medicine is ready to develop along these lines.

The board is also considering how best to recognise the continuing competence of doctors practising sport and exercise medicine. The procedures to document the appraisal, revalidation, continuing medical educational requirements, and professional development of doctors in Great Britain and Ireland is still in its infancy. The Intercollegiate Academic Board of Sport and Exercise Medicine expects to make a positive contribution to the debate as well as supporting doctors practising sport and exercise medicine as a specialty interest or on a full time basis. The board will be available, as the professional body responsibility for standards in sport and exercise medicine, to advise colleges, postgraduate deans, and regional advisers in general practice on the quality of programmes suitable for continuing medical education credits or postgraduate educational allowances. The board may also act as the body that will record the portfolio of doctors who do not naturally fall under the umbrella of one of the more established colleges or faculties.

In summary, the programme being pursued by the Intercollegiate Academic Board of Sport and Exercise Medicine is designed to:

(a) recognise basic specialty training in sport and exercise medicine;

(b) promote one year flexible training opportunities in a wide range of higher specialty training programmes;

(c) develop a four year higher specialty training programme in sport and exercise medicine;

(d) gain recognition for the new specialty by the STA;

(e) establish a system to recognise the continuing competence of doctors practising sport and exercise medicine.

The Intercollegiate Academic Board of Sport and Exercise Medicine must report its progress and plans for future development to the Academy of Medical Royal Colleges in July 2000. The plans summarised above will be the basis of the submission that will hopefully be approved and give further momentum to the eventual recognition of sport and exercise medicine as a fully fledged specialty in Great Britain and Ireland.

DONALD A D MACLEOD 


\section{Postgraduate medical education: methodology}

Sports medicine is a relatively new and rapidly growing specialty that as yet does not have an organised postgraduate training programme. Currently, doctors enter sports medicine from a variety of backgrounds and rely on ad hoc training. If sports medicine is to be encompassed in the NHS, it is important to address the issue of training and organise effective postgraduate training in the specialty. Sports medicine has the opportunity to develop a training programme from a "clean slate", uncomplicated by existing practice. The specialty therefore has the potential to learn from other examples of good practice and avoid some of the problems experienced with higher specialist training in other specialties.

Postgraduate medical education refers to education provided after full registration and before consultant appointment or equivalent career grade. Medical education should be seen as a continuum, with postgraduate medical education supplementing undergraduate education and being continued after appointment to a career post as continuing medical education. ${ }^{1}$ There have been major reforms in the United Kingdom's postgraduate medical education during the last decade, prompted in part by demands for greater harmonisation with other European states. ${ }^{2}$ There has also been increasing realisation of the importance of self directed learning and development of life long learning skills to allow the doctor to keep pace with continually changing medical knowledge. ${ }^{3}$ Previous ad hoc individually organised postgraduate medical education has been replaced in various specialties by structured training programmes providing shorter and more focused training with a predominance of education over service provision. ${ }^{4}$

Such training programmes are overseen and regularly monitored by joint higher training committees or the equivalent set up by the royal colleges to ensure that standards of training are maintained across the country. The committees lay down the criteria for training in the individual specialties and approve training programmes on the basis of suitable facilities in terms of consultant supervision, staffing levels, clinical experience, and opportunities for research. Likewise the committees grant certificates of accreditation (CSST) to trainees on satisfactory completion of specialist training to mark the end of training and show that the doctor has met the requirements for independent practice.

The Department of Health report entitled Training for the future made several recommendations about higher specialist training. ${ }^{4}$ The training programmes should have clearly defined entry criteria and published curricula with clearly stated objectives. The aim should be to convert the trainee into a doctor ready to take up a consultant post and capable of independent unsupervised practice. Training should create a doctor who can keep pace with the rapid advances in medicine, recognise the patient's perspective, appreciate the skills of other health professionals, and work effectively in a team. The programme therefore needs to address not just clinical skills and knowledge, but also other aspects of clinical competence expected of a doctor such as communication skills, attitude, team working, audit, research, teaching, and self directed learning. The training should offer closely supervised practical experience and protected time for both formal teaching and private study. Protected time for teaching applies to both the trainees and the trainers. The trainee should be provided with support. Every trainee should be nominated a specific educational adviser who can offer a channel for communication and give guidance and support. Current training programmes vary as to how they interpret this: some nominate a consultant trainer for each subspecialty attachment, others nominate a supervisor for the entire training programme. The latter arrangement would seem to offer the opportunity to establish a better support mechanism, but care needs to be taken to ensure appropriate selection of a supervisor for the individual trainee.

\section{Teaching the teachers}

Teaching is of vital importance, and those consultants who take on this role should be highly motivated; they should be taught how to teach and their efforts should be valued and rewarded. Teaching offered to trainers should include effective teaching techniques, appraisal and assessment skills, and giving constructive feedback. Teachers need to learn to be facilitators of learning rather than providers of information, and should encourage students to become self directed learners with the desire and skills for life long learning. To achieve this, teachers must provide students with appropriate direction and guidance within a constructive and supportive educational environment. Such skills are generic to all specialties. Relevant courses are becoming more widely available and are usually set up by universities or royal colleges. Consultant trainers need to be made aware of the availability and relevance of such courses and should be encouraged to attend them.

\section{Feedback, appraisal, and assessment}

There should be regular two way feedback between the trainee and trainer, to allow improvements both in the trainee's learning and in the training offered. Training programmes should include integrated and structured appraisal and assessment mechanisms. Assessment should include both formative and summative assessment. Formative assessment should occur during a period of training to provide timely feedback to the trainee with the prime intention of helping him or her to progress. Summative assessment occurs at the end of a period of training to check that the objectives have been achieved. Trainers should also promote self assessment by encouraging trainees to reflect on and critically evaluate their own work, so that they can identify their own strengths and weaknesses. The content of assessment should reflect the objectives of the training programme. Assessment should be competency based and criterion referenced. This involves the setting of clear standards expected of the trainee at various stages in their training. Assessment has proved difficult in many specialties, reflecting the current lack of standards and the difficulties both trainees and trainers find in giving constructive feedback. In addition to informal feedback, there should be formal appraisal sessions, with planned confidential meetings taking place between the trainee and trainer at these times. These meetings provide an opportunity to step back from daily work in order to review and discuss performance and progress, so as to agree an educational action plan designed to help the student to progress.

\section{Subspecialty training}

The final years of training should be flexible and adapted to the individual trainee's needs so as to allow acquisition of subspecialty training or general training according to the 
trainee's future career plans. Training centres should be encouraged to offer subspecialty training in areas of particular local expertise. Currently, such opportunities are not maximised in all specialties or training schemes. Likewise the trainee should be encouraged to transfer between centres to achieve a period of further training in his/her special interest, but again at present such transfer is not always made easy for trainees.

\section{Role of research in training}

It is generally agreed that an understanding of the principles of research and the ability to assess critically the results of published work are essential attributes of a doctor. The skills required include developing an inquiring mind, learning how to design studies, managing projects, collecting data, analysing results, writing reports, and presenting at scientific meetings. ${ }^{5}$ Active participation in research is the most effective means of acquiring such skills. All doctors should therefore be encouraged to undertake research during their training. Unfortunately some of the research currently performed by trainees is of questionable educational value. Common problems contributing to this are poor support and unsatisfactory supervision. Trainees should be supervised by a consultant with an interest in research. There should also be flexibility in the system to allow the trainee the choice to take time out from clinical training in order to carry out a period of research without this adversely affecting his/her future career. $^{36}$

If sports medicine can institute all of the above, it has the potential to develop a model training programme for higher specialist training.

Sheffield Children's Hospital, Western Bank, Sheffield S10 2TH, United Kingdom

GILLIAN LONG

Leeds General Infirmary, Great George Street,

W W GIBBON

Leeds LS1 3EX, United Kingdom

1 Royal Commission on Medical Education 1965-68, Chairman, Lord Todd. Report. London: HMSO, 1968. (Cmnd 3569.)

2 Council Directive 93/16/EEC of 5 April 1993. Official fournal ot the European Commission 1993;36.

3 Calman KC, Temple JG, Naysmith R, et al. Reforming higher specialist training in the United Kingdom: a step along the continuum of medical education. Med Educ 1999;33:28-33.

4 Department of Health. Hospital doctors. Training for the future: the report of the working group on specialist medical training. London: Department of Health, 1993.

5 Neale G. The place of research in the training of physicians. $\mathcal{F} R$ Coll Physicians Lond 1991;25:188-90.

6 Department of Health. Academic and research medicine. Supplement to a Guide to specialist registrar training. London: Department of Health, 1996.

\section{The role of a masters degree as part of higher training in sports and exercise medicine or why do a masters?}

Sports medicine is now recognised as a specialty in some European countries. As an emerging discipline, sports and exercise medicine needs to develop a solid academic footing if it is to gain acceptance by the Royal Colleges in Great Britain and Ireland. A higher professional university degree is a requirement for work in sports and exercise medicine clinics abroad, especially schemes associated with the Fellowship of the Australian College of Sports Medicine. Health insurance companies, professional athletes, and teams now demand a much higher standard of care from their sports physicians, and this makes the higher status of further postgraduate university qualifications even more important.

In Great Britain and Ireland, practitioners engaged in masters programmes develop an understanding of training methods from a wide variety of sports and the prerequisite knowledge to monitor and optimise the health and performance of athletes whether recreational or elite.

The standard postgraduate training schemes are usually hospital based and offer little direct exposure to elite and recreational athletes for practitioners with an interest in sports and exercise medicine. The teaching of musculoskeletal history taking and examination is generally poor even within most hospital orthopaedic departments. Sports medicine relies on a broad based knowledge and is better suited to the general medical training found in the disciplines of accident and emergency and family medicine.

The educational attractions of a masters course are that it provides a multidisciplinary approach to the teaching of functional and applied anatomy, exercise and applied physiology including laboratory based practical fitness testing, and emergency medicine. A knowledge of the techniques and expertise of other practitioners, including physiotherapists, nutritionists, podiatrists, biomechanists, psychologists, coaches, and athletic trainers, is also provided. The teaching of functional clinical anatomy, especially in some universities, has a low priority; however, this knowledge is the key to an understanding of the possible differential diagnoses of most sports related injuries.

The athletes themselves appreciate practitioners with a knowledge of the demands of training and competition for their particular sport. A university based taught masters incorporates sports specific lectures and workshops given by coaches, team medical officers and physiotherapists, and athletes from different sports. Even the best part time, weekend, or distance based course will never be able to address all these areas or pull together the various disciplines that encompass the many facets of sports medicine.

Programmes incorporating research and evidence based medicine are also essential if sports and exercise medicine is to develop. The research thesis required by a masters programme, which is either laboratory or field based and is examined by an external examiner, gives the practitioner an opportunity to develop research skills and a scientific basis for the study of all aspects of sports medicine.

A masters course gives the participants an opportunity to familiarise themselves with the theory, practice, and guidelines for the scientific monitoring and training of athletes from a wide range of sports. The university based masters course here at Trinity College also gives the doctor an opportunity to work with various college sports teams and gain practical experience in how to deal with coaches, athletes, and managers before they act as fully fledged team doctors. It is also essential that they have participated and passed a cardiopulmonary resuscitation course and be able to cope with on field emergencies, particularly potential spinal injuries. A pre hospital trauma/side line care course is a vital element in sports medicine training. It is compulsory to pass both these elements in examinations for the 
Trinity College, Dublin masters course and the diploma in sports and exercise medicine at Bath University.

A full time degree taught partly by research, with academic standards upheld by university external examiners, allows the clinician to develop skills that would be impossible to develop in full or part time clinical practice. The new Intercollegiate Academic Board of Sport and Exercise Medicine plans to develop a curriculum and a four year higher specialty training in sport and exercise medicine.
A unified well structured and coordinated masters programme organised by the universities in Great Britain and Ireland should be an integral part of this scheme.

\section{MOIRA O'BRIEN}

NICK MAHONY

Course Director and Course Coordinator, MSc in Sports Medicine Course Department of Anatomy, Trinity College

University of Dublin, Ireland

email:mobrien@tcd.ie

\section{Fellowship in Sports Medicine}

The fellowship, first offered in 1982, is multifaceted and includes clinical exposure, course work, research, teaching, community work, and medical education. The clinical time is split between primary care sports medicine, orthopaedics, and physiotherapy, with the emphasis on primary care. The fellow, once familiar with the specific sports oriented history and physical, assesses and reviews the cases with one of the primary care doctors and is available at follow up. Training in research is an important part of the programme, and the fellow is required to complete, or have completed, a programme of study leading to a Master of Science degree. The fellow is also expected to organise for publication a clinical or basic science research paper. This paper is often generated from the thesis required for the masters degree.

Sports medicine courses are offered through the School of Human Kinetics at the University of British Columbia on a credit basis. They cover all musculoskeletal and organ systems and how these are affected by sports injury. A further component of the fellows training is teaching, both within and outside the Allan McGavin Sports Medicine Centre, with family practice residents and in the medical and lay communities where the fellow is encouraged to participate in presenting lectures and seminars on a myriad of sports medicine topics. The fellow also participates in a number of sports medicine conferences organised each year by the centre and in national and international conferences.

Community service in the form of medical coverage for a team (either varsity or community based) and for sporting events (tournaments, runs, athletic meets, etc) is also a requirement for successful completion of the programme. The format is flexible, with the fellow spending 2.5 days per week in clinical training and the remainder of the time for course work, research, and sports medicine coverage. We encourage full time participation in the programme. The fellows take the Canadian Academy of Sport Medicine diploma examination on completion of their training at the Allan McGavin Sports Medicine Centre.

Alan McGavin Sports Medicine Centre

JACK E TAUNTON

fohn Owen Pavilion, 3055 Wesbrook Mall

Vancouver, British Columbia V6T 1Z3, Canada

email:jtaunton@interchange.ubc.ca

\section{The German situation}

Over the past century, education in sports medicine and exercise physiology in Germany has undergone various modifications. Furthermore, the reunification of the country over the last decade has caused political and economic changes resulting in fundamental and continuing changes in education and in the professions of general doctors, clinically orientated specialists, and basic and applied scientists in the field of sports medicine and exercise physiology. Currently, doctors in Germany do not have the opportunity to specialise in sports medicine. However, the introduction of such professional training is continuously being discussed. Every fully trained doctor can acquire additional certification in sports medicine. This consists of a course of 120 lessons on theory and practice in sports medicine, including basics and special aspects such as children, top level sports, prevention of injury and rehabilitation, psychology, movement science, biomechanics, and pedagogics, plus 120 lessons on the theory and practice of sports and exercise, covering areas such as prevention of injury and rehabilitation, recreational and elite sports, and also lifestyle, fun, and extreme events. This professional training is completed during a one year appointment as a part time team doctor or a comparable post. Alternatively, the certification in sports medicine can be attained during tenure of a one year full time position in a specially licenced medical unit, such as one of the very few state institutes of sports medicine, Olympic centres, and several university departments. Two years of training on the job as a clinician are a further prerequisite for the certificate.

Academic education in sports medicine and exercise physiology is also of interest to a broad spectrum of non-physicians. German universities provide numerous different courses in the field of physical education. This is also changing for the following reasons. The physical education system is still mainly focused on training to become a teacher specialised for selected school types, and jobs not associated with school teaching are rare. Up until now, there has been no other accepted field of professional activity that requires a highly qualified academic or scientific background. In addition, our educational system is not compatible with the internationally favoured AngloAmerican system. This has encouraged us to reorganise our long standing diploma qualification and implement internationally accepted undergraduate and postgraduate opportunities. At selected universities, the European Network of Sport Science in higher Education using existing concepts such as the European Master in Health and Fitness is under discussion and construction.

German sports medicine and exercise physiology research units, like university institutes, do not exclusively 
focus on science. They also serve as clinical departments with a particular place in the healthcare system. Consequently, the head of such an institution not only is responsible for scientific guidance but also has clinical duties which require him/her to be a licenced doctor. In spite of the fact that this combination of clinical duties and basic science has in the past proved to be an effective generator of relevant ideas for integrative research projects, nowadays internationalisation and top standards in basic and applied science demand sufficient career opportunities for nonphysicians as highly qualified and competitive specialists in exercise physiology and related disciplines. Corresponding requirements on organisation and infrastructure of scientific departments but also new career pitfalls have been identified, but so far only very few consequences have been anticipated, generating continuing controversy.

Another possibly related problem is that neither sports medicine nor exercise physiology are obligatory subjects in medical schools. Thus, only very few medical schools offer facultative lessons in sports medicine or exercise physiology, a matter that has been under discussion for decades.
This discussion is fuelled by the realisation that a knowledge of sports medicine and exercise physiology is of interdisciplinary relevance to many areas, not only in the field of physical education but also in the prevention and treatment of many chronic diseases in particular.

Unfortunately, over the last two decades, this has been complicated by a shortage of money in the university system, healthcare system, and various areas of nonprofessional sport. The economic situation is somewhat inhomogeneous throughout the regions, and integrative and applied research has lost out on resources because of the competitive funding. There is a great risk that the ideas and solutions favoured in the end will be dictated by the budget without sufficient account being taken of the fundamental academic problems, questions, and ideas. However, the multifactorially changing sports medicine and exercise physiology education system in Germany offers huge and exciting opportunities.

RALPH BENEKE

Berlin, Germany
Sports and exercise medicine has a long tradition in Finland. Organised medical care of athletes has been available since the 1930s. The Finnish Society of Sports Medicine was founded in 1939 and is probably the oldest nationwide sports medicine society in the world. Today, the society has about 500 physician members (5.2 million population) and publishes, along with the Finnish Society of Sports Physical Therapists, its own journal (three or four issues a year) and, together with the other Scandinavian societies, the international peer reviewed journal Scandinavian fournal of Medicine and Science in Sports (six issues a year). Organisation of instructional courses, seminars, and symposia on sports and exercise medicine is also an important part of the work of the Finnish Society. Every other year, one of the Scandinavian societies organises the international Scandinavian Congress on Medicine and Science in Sports (300-600 participants). In 1998, this congress was held in Finland.

In 1946, the first sports medical centre was opened at the Olympic Stadium of Helsinki. In 1956, a similar unit was founded in Turku. Today, Finland has six sports and exercise medicine research centres funded by the Ministy of Education (Helsinki, Turku, Tampere, Jyväskylä, Oulu, and Kuopio). Each has a staff of between five and eight full time workers and a varying number of part time workers such as consulting doctors. The tasks of the full time staff are to carry out research work in sports and exercise medicine (research should cover about $50 \%$ of the work), offer sports medical services, exercise tests, laboratory services, doping control, and physical therapy services to competitive and recreational athletes (25\%), look after resident education, and organise symposia and lectures for doctors, medical and physical therapy students, coaches, athletes, and the general public (25\%). In addition to these centres, the University of Jyväskylä, Research Institute of Olympic Sports, and about 10 other sports institutes provide facilities for research, education, fitness testing, and/or sports medical services. One or two private (orthopaedic) sports medicine clinics also operate in the largest cities of Finland.

In 1985, sports and exercise medicine was accepted as a full university based medical specialty in Finland - that is, in line with the other large specialties such as surgery, internal medicine, and paediatrics. From the very beginning, it was recognised that the specialty should be more than just taking care of sporting elite: the basis of the new specialty was accepted to be public health work and medical care of all people who exercise and improving the general wellbeing and health of the population through promotion of an active lifestyle. Until 1998, the education programme in sports and exercise medicine lasted six years, but after the major reorganisation of medical specialties in Finland in 1998, sports and exercise medicine was reduced to a five year curriculum. This would appear to be a backward step, but considering that during the 1998 reorganisation about $50 \%$ of the medical specialties were abolished, the five year curriculum was actually a major victory for sports and exercise medicine in Finland.

Thus, after the six years in medical school, residents of sports and exercise medicine serve an additional five years in a specialisation programme. Eight resident positions are available, and the programme includes one year of general training (as a general practitioner in the community based primary care centres) and four years of specialist training. The entire education programme is based on general practice - that is, the specialty of sports and exercise medicine in Finland is not a subspecialty or fellowship of orthopaedic surgery (or any other full specialty) - although $1-1.5$ years of the specialist training has to be served in at least two of the following areas: surgery, orthopaedics and traumatology, physical medicine and rehabilitation, internal medicine (including rheumatology), clinical physiology, clinical chemistry, paediatrics, neurology, or radiology.

The remaining 2.5-3 years of specialist training is carried out as a resident of the specialty. These resident posts are located in the six sports and exercise medicine research centres mentioned above. During this period of training, the residents take part in practical work as well as a wide selection of instructional courses and symposia on sports and exercise medicine-as a participant as well as a speaker. It is also stated in the curriculum that they must participate in research work during the residency. As a result, many of the resident doctors publish their academic thesis during or after their residency. The specialist training culminates in the national specialist examination, which 
includes seven books and three recent volumes of the selected peer reviewed journals of general and sports medicine.

Today, Finland has over 40 doctors who specialise in sports and exercise medicine, working in universities, research centres, sports institutes, health centres, private clinics, and the Finnish army. In 1988, a society for specialists in sports and exercise medicine was founded. In 1989 , the first full time chair in sports medicine was established, in 1998 one part time professor was nominated, and during the year 2000 one or two additional chairs will probably be established.

Sports and exercise medicine in Finland also faces difficulties. Economics is always a problem. The basic financial support (50-60\% of the budget) for the six sports medicine research centres comes from the Ministry of Education (not the Ministry of Health), emphasising the research work and resident education. However, much of the work is carried out at the expense of the centres' medical services and other money generating activities and therefore their own economic wealth. Secondly, the specialists being trained now may have difficulty in finding suitable jobs. The first 40 specialists are well employed, but the situation will probably not be so easy for the new generation. Perhaps the growth in professional sport will create new opportunities in the near future. Finally, in Finland, we should consider creating a two year postgraduate degree in sports and exercise medicine (subspecialty, fellowship) for those who are already specialists in another branch of medicine. Orthopaedic surgery, physical medicine and rehabilitation, internal medicine (cardiology), clinical physiology, radiology, and general practice at least should have such a programme. This would definitely calm the lively debate on the issue of who is the "true" specialist in the field of sports and exercise medicine.

PEKKA KANNUS

Chief Physician and Head, Accident and Trauma Research Center, UKK Institute, PO Box 30, FIN-33501 Tampere, Finland

JARI PARKKARI

Chief Physician and Head, Research Center of Sports Medicine,

UKK Institute, PO Box 30, FIN-33501 Tampere, Finland

\section{Sports medicine education in Australia}

\section{Fellowship of the Australian College of Sports Physicians (FACSP)}

This is recognised as the specialist training programme in sports medicine in both New Zealand and Australia, although government recognition as a medical specialty in Australia is still awaited. In New Zealand, sports medicine has been recognised as a special discipline.

The term "sports physician" is reserved for Fellows of the Australian College of Sports Physicians (ACSP) and "sports medicine practitioner" is used for all other doctors with a qualification - for example, Master of Sports Medicine, Diploma of Sports Medicine-and/or interest in sports medicine.

Fellowship of the ACSP is obtained after a minimum of seven years approved postgraduate medical experience and training. Trainees must be registered to practise in Australia.

An initial three years of internship or hospital residency and perhaps primary care experience is prescribed before a prospective trainee can sit the part 1 fellowship examination of the college. This consists of two three hour multiple choice examination papers which cover physiology, anatomy, pharmacology, and pathology. It is a college specific examination but equivalence has been granted for part 1 examinations of the Royal Australasian College of Physicians and the Royal Australian College of Surgeons.

Successful completion of these papers confers eligibility to apply for a training position with the Advanced Training Program of the ACSP. At the time of writing, there are 11 training posts in Australia and New Zealand. All teaching is carried out by Fellows of the ACSP and fellows of other specialist colleges appointed by the ACSP, and advanced training takes at least four years. The requirements of each trainee (registrar in sports medicine) are demanding and meticulous. At the completion of advanced training, each trainee must have demonstrated satisfaction from each of her/his supervisors, kept a log of medical experience, undertaken an original research project, and published as first author in an international refereed journal, undertaken formal face to face teaching at least two hours a week, provided team coverage at high level competition, and presented original work (which is reviewed) at each annual registrars conference. A curriculum outlined by the ACSP must be adhered to.

Advanced training allows for a one year "elective" in sports medicine, however, which can be taken as the fourth year of advanced training, but all requirements as listed must be met before fellowship can be granted.

In the third year of advanced training, the fellowship examination may be undertaken. This comprises two three hour written papers, which are composed of multiple choice questions and short answer essay questions, and, if passed, an oral examination. This consists of one long case presentation and a number of short case presentations, which use real patients (not role playing), and a viva voce examination using $x$ rays, bone scans, magnetic resonance imaging scans, blood tests, pulmonary function tests, ECGs, and equipment such as orthoses, prostheses, bicycles, tennis racquets, and footwear. Candidates must pass all sections of these examinations for fellowship and must complete their fourth elective year before fellowship is conferred. The postnominals FACSP are used to indicate Fellowship of the College and expertise as a sports physician.

\section{Master of Sports Medicine (University of Canberra/Australian Institute of Sport)}

This degree is offered to medical graduates from around the world as a fee paying course. No medical registration in Australia is required. The course is conducted over one calendar year at the University of Canberra and the Australian Institute of Sport.

Four nine week terms (900 hours of teaching) cover the basic sciences (physiology, biomechanics, etc), traumatic and overuse injuries in sport and exercise, internal medicine, and special considerations in sport such as doping, medicolegal aspects, special groups, and team coverage. Teaching is face to face in the classroom and at the bedside in sports medicine clinics, and a component of the course includes laboratory experience in cardiology, chest medicine, rheumatology, and podiatry. There is also a compulsory research element which necessitates a comprehensive literature review and research proposal.

Examinations are conducted at the end of each term by written papers (short essays) and by a final clinical 
examination with real patients, and a viva voce examination (with a range of medical imaging, pathology tests, ECG, and lung function tests, etc).

The masters degree is accredited by the ACSP towards advanced training by its registrars.

\section{Master of Medicine (Sports Medicine) (Edith Cowan University)}

This degree is offered by course work as a distance education programme to medical graduates around the world. It is operated by Edith Cowan University (in Perth, Western Australia), and is serviced by the Australian Institute of Sport. It is a fee paying course and can be completed in a minimum of two years. A number of modules have been prepared which cover the basic sciences (anatomy, physiology, nutrition, psychology, etc.), research methodology and statistics, trauma and overuse injury, aspects of internal medicine, and special topics such as doping in sport. Each module comes as prepared text and supporting references, together with recommended reading and core texts.

A Diploma in Medicine (Sports Medicine) has been offered to those who have completed the first half of the course.

Examination is by "closed book" short essay questions at the end of each module, and a component of practical teaching (and assessment) is specified before either a diploma or masters degree is conferred.

\section{Certificate of Advanced Sports Medicine (Sports Medicine Australia South Australian branch)} This course is being proposed for CME accreditation by the Royal Australian College of General Practitioners (RACGP) and is intended for the development of skills in sports medicine by general practitioners. Sports Medicine Australia is a national body comprising clinicians, scientists, educators, and administrators with an interest in sports medicine. It is essentially multidisciplinary and aims to serve its own members by the provision of education services and to serve the community.

The Certificate is a fee paying course which is conducted as a set of three compulsory unit modules. The modules cover the scientific basis of clinical sports medicine-for example, anatomy, physiology, nutrition-special considerations in sports medicine-for example, soft tissue injury, drugs in sport, screening, dental problems - and clinical sports injury management (including diagnosis and management of injury, data acquisition, and research).

The time commitment over the three units totals 74 contact hours of teaching plus 80 hours practical experience. Teaching is carried out in small groups, using formal lectures, case studies, videotapes, and clinical software. Teachers are drawn from general practice, orthopaedics, musculoskeletal medicine, and sports medicine. Candidates spend time in sports medical clinics, operating theatres, and rehabilitation centres.

Assessment is by take home examination papers, practical assessments, review of research activity, and self evaluation.

\section{University of New South Wales courses in sports medicine}

The University of New South Wales (UNSW) in Sydney offers three fee paying distance education courses in sports medicine. These are available to medical graduates around the world.

The Graduate Certificate in Sports Medicine comprises four subjects (sports injuries 1 and 2, medical applications of exercise 1 and 2) which are delivered over one to two years.

The Graduate Diploma in Sports Medicine covers the content of the Graduate Certificate and adds four modules on applied sports medicine, sports science, nutrition, pharmacology, psychology, and clinical biomechanics. This is presented over two to three years.

The Masters Degree in Sports Medicine is offered over two to three years and adds research methods and a research project to the content of the Graduate Diploma.

Teaching uses videotape, CD-ROM, email, and webbased teaching and standard texts and reference papers. Face to face teaching is arranged, and progress is monitored with log books and a case history. Examination is by supervised written examinations at the end of each 14 week teaching period (which covers one "subject"). A final clinical examination is structured on the objective structured clinical examination (OSCE) model.

Teaching staff at UNSW comprise sports physicians and researchers.

PETER FRICKER

Acting Coordinator Sports Science and Sports Medicine AIS,

Chair of Sports Medicine,

University of Canberra,

Canberra, Australia

\section{Educating Australian physiotherapists: striving for excellence in sport and exercise medicine}

Physiotherapists play a major role in sports medicine delivery and research in Australia, a country renowned for its sporting achievements and sporting culture. Sports medicine in this country is a relatively young specialty which has undergone rapid development particularly since the 1956 Melbourne Olympic Games. Educating physiotherapists in sports and exercise begins in undergraduate training where a large proportion of the physiotherapy course focuses on theoretical knowledge and practical skills in the neuromusculoskeletal area. After graduation, further sports physiotherapy experience can be gained through formal postgraduate university qualifications or a variety of professional development activities.

The first formal education programme for students in the area of physiotherapy began in Australia at the University of Melbourne in the early 1900s. Initially, registration to prac- tice physiotherapy in Australia was licensed under the Massage Registration Board and the Massage Act. In the 1970s, under the auspices of the Physiotherapy Registration Board, physiotherapists in Australia were granted primary contact practitioner status. This was a first in the world for physiotherapy. The responsibility associated with primary practitioner status had a profound effect on undergraduate education requiring an emphasis on differential diagnosis by way of clinical reasoning and clinical decision making.

\section{Undergraduate training}

In Australia in the year 2000, seven universities offer physiotherapy undergraduate programmes with about 650 students in total graduating each year. Two more programmes have started and will have graduates in the near future. A further university has advertised for a new 
chair of physiotherapy, and other universities are considering establishing programmes. This is a clear demonstration of the popularity of physiotherapy as a choice of career for Australian students. In particular, many students are interested in the area of sports physiotherapy. The programmes are very competitive to enter and the students entering the programmes come from the top $2-5 \%$ of secondary school leavers. There is also a great demand for places from students who have completed other degrees and wish to enter physiotherapy-for example, science and human movement (physical education). Although each university has its own entry requirements, these would all include English and a variety of biological and physical science subjects. At present, all physiotherapy programmes in Australia are four year bachelor degrees. Plans are in place at a number of universities for entry level masters programmes. Physiotherapy curriculums from all universities must now be accredited by the Australian Council of Physiotherapy Regulating Authorities (ACOPRA). There are no national examination requirements for graduating physiotherapists, as the accreditation process is rigorous covering all aspects of physiotherapy programmes.

In the environment in which physiotherapists will work in the 21 st century, graduates should understand the need and have the desire to be lifelong learners responsible for their own professional development. To continue to strive for excellence, educational programmes need to reflect the demands of the community for health professionals well versed in evidence based practice with the ability to communicate effectively with their stakeholders. With these societal requirements, the emphasis throughout Australian undergraduate physiotherapy educational programmes is a framework of study that focuses on biomedical science subjects integrated with extensive clinical experience and evidence based physiotherapy practice.

Acknowledging the fact that most Australian physiotherapists work in the area of musculoskeletal and sports physiotherapy, emphasis in the undergraduate programmes is on those subjects particularly relevant to sport and exercise including biomechanics, kinesiology, physiology, and in particular exercise physiology, anatomy and applied anatomy, neuroscience, motor control, and soft tissue pathologies. The understanding of normal structure and function and therefore the ability to analyse abnormal structure and function is a major element of sports physiotherapy practice. Added to this, students develop skills in the management of sporting injuries, exercise prescription, injury prevention, and health promotion. Many undergraduate students gain first aid and sports trainer qualifications in order to further their experience in sports coverage. Such programmes ensure that the graduating physiotherapist is well placed to take a significant role in the discipline of sports medicine.

Following on from their undergraduate education, there are a number of avenues that graduates can pursue to further their knowledge and skills in sports physiotherapy, including formal postgraduate tertiary qualifications, professional development, continuing education and specialisation within the framework of the Australian Physiotherapy Association (APA).

\section{University based graduate sports physiotherapy education}

All of the schools of physiotherapy provide postgraduate education specifically for physiotherapists. This encompasses both course work and research streams. In the sports and exercise area, there are a variety of coursework awards including sports physiotherapy, exercise rehabilitation, manual therapy, neuromuscular physiotherapy, and hydrotherapy. Recently professional doctorates have been intro- duced that will allow clinicians to undertake original research related to their clinical practice as well as advanced clinical work. The multidisciplinary nature of sports medicine in Australia is further supported by other graduate programmes relevant to sports and exercise medicine which are available to a range of suitably qualified health professionals.

The research pathway is through masters and doctoral programmes. These require the student to undertake substantial supervised original research, which is examined through a major thesis. The students' topics reflect the research strengths of the individual institutions and may include basic science or clinically based projects. Australian sports physiotherapy research has been published internationally, and topics include lumbar stabilisation exercises, prevention and treatment of hamstring injuries, shoulder rehabilitation programmes, risk factors for stress fractures in athletes, effects of external ankle supports, proprioception and ankle sprains, postoperative rehabilitation of anterior cruciate ligament reconstructions, and pathophysiology of patellar tendinosis.

\section{Continuing education through a national body}

A variety of sources provide continuing education in the area of sports and exercise medicine to the practicing physiotherapist. The major provider of this education is the APA, which was formed in 1940 and today represents more than $80 \%$ of registered physiotherapists. A primary focus of the APA is to ensure the maintenance of standards of practice of physiotherapy in Australia. The APA facilitates this in a number of ways. In 1999, it introduced a mandatory continuing education programme to promote excellence in physiotherapy practice and an understanding of the need for lifelong learning. This is a competency based model which is very broad in its scope and requires members to be responsible for their own continuing professional development in a framework of continuing education. The APA has also accepted in principle a Charter of Educational standards. This document facilitates the APA to work with universities and national special groups to promote and support appropriate standards for the training of physiotherapists in areas of clinical specialty such as sports physiotherapy. The APA Charter of Educational Standards is based on the relation between course outcomes and defined levels of competency. This strong link between the professional association and the universities acknowledges that both sectors provide different ongoing educational opportunities that allow physiotherapists to be constantly enhancing their practice.

Sports physiotherapy was one of the first specialty areas developed within the APA during the 1960s. It is currently one of the largest clinical areas in the association representing practitioners working in all sectors including private practice, sporting clubs, the national and state sports institutes, public hospitals, and community centres. Members of the National Sports Physiotherapy Group have access to continuing education in the form of lectures, seminars, workshops, and sports courses. They are encouraged to participate in organised sports coverage and are required to maintain current first aid certificates.

The APA is in the midst of developing a process of specialisation, which will encourage and enable their members to continue to develop their expertise in their areas of interest. This specialisation process will be multilevel and will reflect formal postgraduate qualifications as well as continuing education. The APA Sports Physiotherapist title is awarded to physiotherapists who attain a nationally recognised academic and clinical standard paving the way for entry into the specialisation process. Criteria include involvement with sporting teams, coverage of sports events, 
continuing professional education in sports physiotherapy, teaching in the area, and promotion of the discipline through research, publications, community service, and community education in sports injury prevention and management. APA sports physiotherapists maintain their title through a mandatory continuing professional development scheme. Benefits of achieving the title include raised public awareness of sports physiotherapy and the specific skills that title holders possess, enhanced marketing opportunities, recognition of the title by outside agencies, and greater opportunities for employment in the sports and exercise medicine setting.

\section{Participation in other activities}

In Australia, the multidisciplinary nature of sports medicine has been facilitated by the establishment of Sports Medicine Australia (SMA). This organisation is Australia's peak authority on all issues relating to sports medicine, sports science, and exercise for the physically active. It is a national umbrella body representing a membership base of health professionals, sporting organisations, and individual participants at both the grass roots and the elite level. Physiotherapists show a commitment to excellence in sports medicine by their level of participation in SMA. For example, membership (of the 3340 members in SMA, 22\% are physiotherapists), committee participation, and organisation of and attendance at the annual scientific conference. In the past six years, three physiotherapists have been recipients of the Young Investigator Award for outstanding research at the SMA conference. Many other physiotherapists also present their research at this forum.

\section{Conclusion}

Educating physiotherapists in sports and exercise science continues to develop as new knowledge and evidence based research is made available. There is a strong ethos in physiotherapy for continuing education and professional development. The commitment by the APA and universities to continue to develop programmes that strive for excellence ensures that Australian physiotherapists are at the forefront of sports medicine practice and research.

KIM BENNELL GILLIAN WEBB

Centre for Sports Medicine Research and Education

School of Physiotherapy, University of Melbourne

Parkville, Melbourne, Australia

\section{What is a sports medicine specialist? A pilot study}

\begin{abstract}
Aim
Sports medicine is a rapidly expanding and developing specialty in the United Kingdom, but there is, currently, no defined training programme or higher career specialist qualification for those wishing to work in this field. A Medline search using keywords "sports medicine", "specialist", "training", and "qualities" found no literature to help define this specialism. The aim of the study was to help define the role of the sports medicine specialist. The specific objective was to seek consensus among those practitioners already working in the field on those qualities considered desirable or essential in a sports medicine specialist.
\end{abstract}

\section{Method}

The study used a modified Delphi technique to seek the views of all 13 doctors in Northern Ireland who possess the basic qualification of a Diploma in Sports Medicine and who work in a variety of clinical settings. In the first round, we invited these doctors to record all those qualities they considered important for a sports medicine specialist under 11 headings (table 1) identified from similar Delphi studies. ${ }^{1-13}$ We included examples of these studies to help illustrate how this technique had been applied in defining other professional roles and also relevant consensus statements. ${ }^{14} 15$

\section{Table 1 Areas of expertise considered}

\begin{tabular}{ll}
\hline A & Access, availability, and administration \\
B & Clinical skills \\
C & Education, teaching, and research \\
D & Team work \\
E & Use of resources and investigations \\
F & Ethics \\
G & Communication skills \\
H & Application of knowledge \\
I & Treatment modalities \\
J & Self management skills \\
K & Practical sports applications \\
\hline
\end{tabular}

In round two, the list of all attributes was circulated to the 13 panel members and each was asked to evaluate their importance from "strongly agree", "agree", "neither", "disagree" to "strongly disagree". Responses were collated and analysed using SPSS software with numerical values being allocated to each response $(1=$ strongly disagree to $5=$ strongly agree).

\section{Results}

Nine of 13 panellists (69\%) completed round one and provided a total of 851 responses. These results were collated and, after elimination of duplicate responses, 329 suggested attributes remained. Eleven of 13 panellists (85\%) completed round two. The 18 responses attracting the highest mean scores after round two are shown in table 2 .

\section{Table 2 Top 18 rated qualities}

Score Quality

4.91 Can ensure injured athlete is transferred safely in emergency situation

4.91 Should be competent at cervical spine immobilisation and protection.

4.91 Should have appropriate medical insurance

4.82 Updates and maintains clinical skills

4.82 Be very competent at full musculoskeletal examination

4.82 Should be competent at CPR/basic life support

4.82 Should be competent in assessment and management of emergencies on the field

4.82 Remains sober while on duty

4.73 Identifies and prioritises urgent cases by clinical need

4.73 Available for referral, including urgent referral from general practitioners

4.73 Aware of legal implications and responsibilities of involvement in sports medicine

4.73 Knowledge and understanding of how injury affects sport

4.73 Ability to take detailed systematic, general, and sports related history

4.73 Ability to perform detailed, systematic general and injury related examination

4.73 Ability to assimilate information from history and examination

4.73 Postgraduate qualification in sports medicine, Diploma in Sports Medicine, or equivalent

4.73 Has access to physiotherapist

4.73 When the sports participant is a child/adolescent, the doctor must give first consideration to the participant's growth and stage of development ${ }^{\star}$

*Taken from the World Medical Association declaration on the principles of health care for sports medicine. ${ }^{14}$ 


\section{Conclusions}

This consensus study highlights areas of ethical, medicolegal, and emergency medicine as being those most desirable or essential in a sports medicine specialist. A number of these statements could equally apply to any medical practitioner. We have only identified the top 18 qualities. It is interesting to note that, of the 311 other qualities identified, the lowest scores of 2.88 and 3 were received by the statements "has a formal attachment to a team or sport" and "experience as a player at different levels" respectively. Furthermore no quality was rated 5 by all respondents.

This is a small geographically isolated study but it uses a recognised method to seek consensus among those who have shown their commitment by undertaking a higher specialist qualification. A further, United Kingdom wide study is in preparation.

We would like to acknowledge the invaluable help received from the participants in this pilot study. They are M Webb, D McCreary, P McCormack, D Irwin, T Forde, B Fair, M Cunningham, M Cullen, I Corry, E Abernethy, M Hampton. B THOMPSON

Sports Medicine Clinic, Craigavon Area Hospital, Portadown, Northen Ireland BT63 $5 Q Q$

O MCNALLY S O NEILL

D MACAULEY

Institute of Postgraduate Medical and Health Sciences, University of Ulster, Ulster BT37 OQB, Northern Ireland
1 Stewart J, O'Halloran C, Harrigan P, et al. Identifying appropriate tasks for the preregistration year: a modified Delphi technique. BMF 1999;19:224-9.

2 Baldwin PJ, Paisley AM, Paterson Brown S. Consultant surgeon's opinion of the skills required of basic surgical trainees. Br F Surg 1999;86:1078-82.

3 Williams PL, Webb C. The Delphi technique: a methodological discussion. f Adv Nurs 1994;19:180-6.

4 Everett A. Piercing the veil of the future. A review of the Delphi method of research. Professional Nurse 1993;3;181-5.

5 Crisp J, Pelletier D, Duffield C. It's all in a name. When is a "Delphi Study" not a Delphi Study? Australian $\mathcal{F}$ Adv Nurs 1999;16:32-7.

6 Hollis N, Davis I, Reeb R. Use of a Delphi technique to prioritize clinical nursing research needs. Nursing Connections 1995;8:65-70.

7 Jairath N, Weinstein J. The Delphi methodology (part one): a useful administrative approach. Canadian fournal of Nursing Administration 1994;7:2942

8 Goodman CM. The Delphi technique: a critique. F Adv Nurs 1987;12:72934

9 Duffield C. The Delphi technique. Australian fournal of Advanced Nursing 1988;6:41-4.

10 Gibson JME. Using the Delphi technique to identify the content and context of nurses' continuing professional development needs. fournal of Clinical Nursing 1998; 7:451-9.

11 Campbell SM, Roland MO, Quayle JA, et al. Quality indicators for general practice: which ones can general practitioners and health authority managers agree are important and how useful are they? F Public Health Med 1998; 20:414-21.

12 McKenna HP. The Delphi technique: a worthwhile research approach for nursing? 7 Adv Nurs 1994;19:1221-5.

13 Holden J, Wearne J. Membership by assessment of performance: developing a method for assessing established general practitioners. Br $f$ Gen Pract 2000;50:231-5.

14 Board of Science and Education. Sport and exercise medicine: policy and provision. London: British Medical Association, 1996.

15 Royal College of General Practitioners, General Practitioners Committee. Good medical practice for general practitioners - draft document for consultation. London: Royal College of General Practitioners, 1999.

\section{Introduction}

The formation of the Intercollegiate Academic Board in Sport and Exercise Medicine represents the first step towards recognition of sport and exercise medicine as an individual specialty, with its own higher specialist training programmes, leading to the establishment of sport and exercise medicine departments within the NHS. However, sports medicine is not an exclusively postgraduate activity and there is increasing interest among medical students. The opportunity for students to direct their own learning goals is in keeping with changes to undergraduate medical education suggested by the General Medical Council (GMC) in their paper entitled Tomorrows' doctors. ${ }^{1}$ One of their recommendations was to supplement the core curriculum with "special study modules", offering students the opportunity to study, in depth, areas of particular interest. This "new" undergraduate curriculum was introduced into medical schools in the academic year 1997/1998.

Our aim was to study the level of interest in the teaching of sport and exercise medicine in undergraduate medical schools, with specific objectives to record the proportion of schools with formal and informal teaching of sport and exercise medicine, the extent of teaching, and in what context it was taught.

\section{Method}

This was a questionnaire study of medical schools in the United Kingdom and Ireland. The first draft of the questionnaire was drawn up by the authors. It was appraised for content and face validity by six members of the Northern Ireland Sports Medicine Interest Group, who had attended five different medical schools and each of whom was involved in sports medicine teaching at some level. The questionnaire was sent to the deans of all medical schools throughout the United Kingdom and Ireland, with a postal reminder after three weeks and a phone call to the secretary to the dean after a further three weeks. Respondents were asked to identify in which year sport and exercise medicine was formally taught as a lecture, as a study module, or as a clinical attachment and we used the following definitions to promote consistency. A study module was defined as: a student undertakes a period of study into an area normally outside the medical curriculum. It may be research based, an assignment or in depth clinical study. A clinical attachment is where a student is based at a department, alone or with a group of students, and clinical experience and teaching in sport and exercise medicine is coordinated by that department.

\section{Results}

Of 30 questionnaires issued, 26 were completed and returned, giving a response rate of $87 \%$. Seven medical schools taught sport and exercise medicine in a formal context within the core curriculum, and, in six schools, sport and exercise medicine was offered as an optional module. The proportion of students who were taught sport and exercise medicine ranged from $10 \%$ to $100 \%$ in different schools. We identified in which year sport and exercise medicine was formally taught as a lecture, as a study module, or as a clinical attachment (table 1).

Table 1 Provision of education in sports and exercise medicine in medical schools

\begin{tabular}{llll}
\hline Year when available & Lecture & Study module & Clinical attachment \\
\hline Year 1 & 4 & 1 & 1 \\
Year 2 & 4 & 5 & 1 \\
Year 3 & 2 & 6 & 2 \\
Year 4 & 1 & 4 & 3 \\
Year 5 & 1 & 1 & 3
\end{tabular}

Results are expressed as number of medical schools where this is available. 
Table 2 Examinations in sports and exercise medicine

\begin{tabular}{ll}
\hline Type of assessment & Number of medical schools \\
\hline MCQ & 4 \\
OSCE & 4 \\
Written exam & 2 \\
Written project/coursework & 1 \\
Case presentation & 1 \\
No formal assessment & 1
\end{tabular}

When asked which specialists were primarily responsible for teaching sport and exercise medicine, an accident and emergency consultant, general practitioner, orthopaedic surgeon, and rheumatologist were each cited once and a sport and exercise medicine consultant was cited on three occasions. Non-clinicians identified included a lecturer in anatomy, an exercise physiologist, and a biochemist. We were also interested to record that formal sport and exercise medicine assessment took place in 12 medical schools in a variety of formats (table 2)

Respondents were asked about other opportunities for students to obtain further teaching in sport and exercise medicine. Of those who responded, two universities offered an intercalated degree in sport and exercise medicine, 10 would allow students to undertake an elective in sport and exercise medicine, and seven stated that there was an opportunity for interested students to attend additional sport and exercise medicine clinics. Only two stated that their university had ever awarded a higher research degree $(\mathrm{MD} / \mathrm{DM} / \mathrm{PhD})$ to a medical doctor in this discipline.

Those universities that did not currently teach sport and exercise medicine were asked if they intended to introduce undergraduate teaching in sport and exercise medicine within the next five years. Five medical schools replied in the affirmative and nine replied that they did not intend to introduce teaching. The most important barriers to the introduction of undergraduate teaching in sport and exercise medicine were "no space in the current curriculum" (four universities), "there is enough sport and exercise medicine taught informally during normal teaching" (four universities), or "no-one qualified to teach sport and exercise medicine in the university" (one university).

\section{Discussion}

Sport and exercise medicine is a relatively new discipline, which has not yet achieved formal recognition as a specialty. According to the findings of this single study, it is taught either formally or informally in 13 of the 28 medical schools who replied to our questionnaire. A further five intend to introduce teaching within the next five years. There is considerable optimism that the Intercollegiate
Academic Board will promote specialty recognition, ${ }^{2}$ and if, in five years time, two thirds of medical schools include sport and exercise medicine in undergraduate education, the future is bright. It is also interesting to note that almost all those who teach the discipline have some form of assessment, which may be interpreted as a further sign that it is taken seriously.

Medical students would prefer more exposure to sport and exercise medicine, applaud recent developments, and even suggest compulsory sports medicine education. ${ }^{3}$ General practitioners think likewise, and, in a recent survey, $72 \%$ felt inadequately trained to practice sport and exercise medicine, $76 \%$ would welcome more training, and $36 \%$ felt that their undergraduate orthopaedic training was of no value in primary care. ${ }^{4}$ The Intercollegiate Academic Board of Sport and Exercise Medicine hopes that the development of postgraduate training programmes in sport and exercise medicine will encourage universities to recognise the value of teaching special study modules and electives in the discipline. ${ }^{5}$

Sport and exercise medicine is a multidisciplinary specialty, which has the potential to provide a medical student with valuable learning opportunities at various stages of his/her training. With particular interest in the health benefits of exercise, there are important public health implications. One could argue strongly that sport and exercise medicine is well placed to meet the recommendations of the GMC for the medical curriculum and that it should become an integral part of the curriculum in all medical schools. It is difficult to know who should be teaching it at present, and this is reflected in the variety of doctors identified as responsible for teaching.

Department of Sports Medicine, Musgrave Park Hospital

M CULLEN Belfast BT9 7FB, Northern Ireland

O MCNALLY S O NEILL D MACAULEY

Institute of Postgraduate Medical and Health Sciences

University of Ulster, Ulster BT37 OQB, Northern Ireland

1 Education Committee of the General Medical Council. Tomorrows' doctors. London: General Medical Council, December 1993.

2 MacLeod D. Sports medicine: vision for the future. Br $\mathcal{f}$ Sports Med 2000;34:

3 Baby B. What is sports medicine? Medical students don't know. Br $\mathcal{F}$ Sports Med 2000;34:73.

4 Buckler DGW. General practitioners' training for, interest in, and knowledge of sports medicine and its organisations. Br f Sports Med 1999; 33:360-363

5 MacLeod D. The Intercollegiate Academic Board of Sport and Exercise Medicine. Br F Sports Med 1999;33:73-74. 